\title{
Acknowledging residual risk behind levees: Examples from the USA, France, and Quebec (Canada)
}

\author{
Anna Serra-Llobet ${ }^{1,2, a}$, Rémy Tourment ${ }^{3}$, Antonin Montané ${ }^{4}$ and Thomas Buffin-Belanger ${ }^{5}$ \\ ${ }^{1}$ University of California Berkeley, California, USA \\ ${ }^{2}$ IMéRA, Aix-Marseille Université, France \\ ${ }^{3}$ INRAE, Aix-en-Provence, France \\ ${ }^{4}$ CEREG, Gémenos, France \\ ${ }^{6}$ Université du Québec à Rimouski, Québec, Canada
}

\begin{abstract}
Although hydraulic infrastructure such as levees remain important for flood risk management in the USA, France, and Quebec (Canada), there is increasing emphasis on non-structural measures, such as regulatory flood maps, to reduce exposure and vulnerability, e.g., preventing people from building in high hazard areas. One key concept related to areas protected by levees is that of "residual risk", i.e., the risk from floods greater than the design standard of the levees (levee overtopping), and from levee breach. In this article, we review the legislative framework for regulatory flood maps in the US, France, and Quebec (Canada), compare restrictions on land use within the designated high-hazard zones, and compare how residual risk behind protective structures is taken into account (or not) in regulatory flood maps. Comparing the Flood Insurance Rate Maps (FIRMs) in the USA with the "Plans de Prévention du Risque d'Inondations" (PPRi) in France and the "Cartes de Zones Inondables" in Quebec, we find big differences in how the USA, France and Canada manage residual risk behind the levees.
\end{abstract}

\section{Introduction}

For many years, structural (protection) measures have been central to flood risk management in the USA and in France, with a focus on reducing the hazard component of risk. However, over time, different dams and levees have shown the limitations of the structural measures approach to managing risks (for example, the 2005 floods in New Orleans during Hurricane Katrina, the 2010 floods in La Faute-sur-Mer, France, during the storm Xyntia, and the 2019 floods in Sainte-Marthe-sur-le-Lac in the suburbs of Montreal, Quebec). Flood risk management behind levees has evolved significantly in the last decades, especially after these events, moving from a more engineering oriented view that focuses on "controlling" the hazard with the use of structural works to a more holistic understanding of the concept of risk, which takes into account the "residual risk" behind the levees and states that there is something society can do in their everyday human activity and public policy, sharing, thus, the responsibility of flood risk management between different levels of government and the individuals. To this end, there are two kinds of maps that are critical to manage residual risk behind levees. The first are "regulatory flood maps", which show the area within the floodplain where land use regulation and building codes apply. These maps are based on hazard maps and can also regulate other aspects of flood risk (insurance, emergency management, risk communication, etc.). These set of maps are available to the general public since one of the main goals is to promote risk awareness and wise use of floodplains. A second set of maps is focused on the performance of the hydraulic infrastructures and show the potential consequences of overtopping or levee breach. In the USA these maps are developed by the USACE under the Levee Safety Program (LSP) but are not available to the general public for safety issues. In France these maps correspond to the maps included in the "Etudes de Dangers" (Hazard Studies) and are public although they are not widely and systematically disseminated. The idea is to complement the information from the regulatory flood maps. These second set of maps are usually created to help levee owners to prioritize investment for the maintenance of the hydraulic infrastructures or to communicate risk behind levees. This article is focused on the first set of maps.

Regulatory flood maps such as the Flood Insurance Rate Maps (FIRMs) in the USA, the Flood Risk Prevention Plans (Plans de Prévention de Risque d'Inondations) (PPRi) in France, and the Flood Zone Maps (Cartes des Zones Inondables) (CZI) in Quebec, have become critical tools to manage flood risk behind levees since they can create very different scenarios of exposure and 
vulnerability that local and national governing agencies will have to face when managing flood risks in the future. These regulatory flood maps focus on the reduction of vulnerability, since they can discourage or forbid further development in the floodplain (reducing exposure in high hazard zones) or require building codes for existing and/or new developments located in the regulatory floodplain, what can increase the capacity to cope with a flood event. While management of flood risk has been widely discussed in the literature, less has been published on the effect of levees and the residual risk posed to lands behind them (Serra-Llobet et al., in review).

\section{Legislative frameworks for regulatory flood maps in the USA, France and Canada: Brief summary}

During the late 1960s, the 1970s and the 1980s, big reforms in the flood-related policies in the USA, France and Canada shifted their national approaches, at that time mainly focused on flood control through hydraulic infrastructures, to a more holistic flood risk management approach that incorporated land use planning as a critical tool to reduce exposure and vulnerability to floods. Flood hazard maps became the cornerstone of these policies filling a critical gap, as there were hardly any maps at that time. These policies were created to discourage developments in hazardous areas or to require building codes such as elevating structures, and, in the case of the USA and France, also to create an insurance system that allowed those affected by floods to be able to recover faster. In the case of the USA, the maps were directly linked to the flood insurance system while in France they were not.

\subsection{Legislative framework for regulatory flood maps in the USA: The National Flood Insurance Program (NFIP) (1968)}

In the USA the regulatory flood maps, as the name indicates, are actually Flood Insurance Rate Maps (FIRMs). They are produced at a community scale and are a separate document from communities comprehensive/urban plan. The FIRMs are the key element of the National Flood Insurance Program (NFIP), which was created by Congress in 1968 under the National Flood Insurance Act, and amended significantly in 1969, 1973, and 1994.

The basic idea was that the federal government would provide subsidized flood insurance if local communities agreed to regulate land use within the established flood hazard area, set as the extent of the 100-year (or 1\% probability) flood to keep development out of flood-prone areas (Eisenstein et al., 2007, Burby, 2001). The NFIP is a voluntary program, which means that if a community doesn't want to participate in the program, they don't have to adopt the map or ordinance. In that case, they will not be eligible for post-disaster funding or subsidized flood insurance. Because of the voluntary nature of the program, FIRMs do not cover the whole USA territory, and some maps are now outdated (Johnson et al., 2020).
If a levee is constructed with a 100-year flood standard of protection, the area behind the levee is then also "removed" from the 100-year flood prone area, even if the land lies below sea level. Then, areas behind accredited levees are considered "out" of the regulatory floodplain and the area is shown as a "Shaded Zone X". An accredited levee system is a system that FEMA has determined to meet the design, data, and documentation requirements of the Title 44 of the Code of Federal Regulations (44 CFR 65.10). This determination is based on a submittal, by or on behalf of a community, which includes documentation certified by a registered professional engineer.

This has created a false sense of security, which has fostered the increase of developments behind levees, what is known as the "levee effect" (White, 1945). In 2005 flooding by Hurricane Katrina killed over 2,100 people and caused damages exceeding 125 billion dollars (2005\$US). This disaster, caused largely as a result of levee failures, increased public awareness of residual risk behind hydraulic structures. Although protected areas behind accredited levees are mapped by FEMA, flood insurance is not obligatory (but highly recommended). However, warning systems are required in these areas.

\subsection{Legislative framework for regulatory flood maps in France: the Cat'Nat' System (1982) and the Flood Risk Prevention Plans (PPRi) (1995)}

Unlike the USA, in France regulatory flood maps are not directedly linked to the insurance system. In 1982 the French government passed two new laws, the Natural Catastrophes Law (Catastrophes naturelles), known as the Cat'Nat', related to the flood insurance system, and the Flood Exposure Prevention Law (1982), related to land use planning (including the maps).

On the one hand, the Cat'Nat' System was initially created to insure catastrophic floods, i.e., floods larger than the $10 \mathrm{y}$ flood, and excluding small repetitive losses, and four other natural disasters: landslides, avalanches, earthquakes and volcanic eruptions. Since 2003 it also covers damages due to soil subsidence resulting from repeated droughts. The entire population is covered by this public flood insurance, which is paid by a tax on insurance premiums on homeowners and automobile insurance of $12 \%$ and $6 \%$, respectively (Barraque, 2014).

On the other hand, the Flood Exposure Prevention Law (1982) created risk exposure plans, which include regulatory maps for different natural hazards. After the 1995 a new law renamed the plans to risk prevention plans, known as PPR (Plan de Prévention des Risques). In the case of riverine floods, they are called flood risk prevention plans or PPR-i (Plan de Prévention des Risques d'Inondation) and for coastal floods they are called PPR-1 (Plan de Prévention des Risques Littoral). The main idea in the French approach is that everybody in France is insured for catastrophic events under the Cat'Nat' System but, on their side, local authorities must restrict developments in hazardous zones.

The 1995 Law created the Major Natural Hazard Prevention Funds (Fonds de Prévention des Risques Naturels Majeurs), also known as the Barnier Fund, which 
allowed to used part of the Cat'Nat' pool for expropriation and amicable acquisitions of buildings in high hazardous zones. The Barnier Fund also covers other type of preventive measures, such as giving financial support to finish the drafting of PPR and some preventive actions taken to implement the PPR (Barraque, 2014).

In France, the PPR-i are created by the "Préfectures", local representatives of the national government. Although it does not constitute an urban planning document itself, the PPRi is the document that governs urban planning in the floodplains in France since 1995 (MATE-MTEL, 1999). Regulatory flood maps are obligatory in flood prone areas. In the PPRi the area behind levees is part of the regulatory flood prone area, and land use restrictions, building codes, emergency measures and risk communication are mandatory.

\subsection{Legislative framework for regulatory flood maps in Canada and Quebec: The National Flood Damage Reduction Program (1975 to early 2000s) and Quebec's Riverbanks, Riparian Zones and Floodplains Protection Policy (1987)}

Canada created the Flood Damage Reduction Program (FDRP) in 1975 with the goal to reduce flood damage and prevent loss of life by discouraging development in areas vulnerable to floods (Millerd et al., 1994). Unlike the USA and France, Canada didn't create an insurance system. With a change in government, the FDRP was phased out starting in the early 1990s and by the last of the agreements expired in 2000 (de Loë, 2000).

Although there is no longer a federal flood management program, Natural Resources Canada (2018) developed flood mapping guidelines to help provinces generate maps. These guidelines are not obligatory and provinces like Quebec have their own methods to map the regulatory flood area. Quebec mapping methods are linked to the Riverbanks, Riparian Zones and Floodplains Protection Policy (PPRLPI, "Politique de protection des rives, du littoraux et des plaines inondables") enacted by the Gouvernement du Québec in 1987 and amended on several occasions since (1996, 2005, 2008, 2015, 2018). Among other considerations for the fluvial space, the PPRLPI describes the minimal buildings codes and land use restrictions in the regulatory floodplains. Quebec has also developed the hydrogeomorphological approach (adopted from France) in order to produce multi-hazard maps to inform land use planning.

The regulatory flood maps in Quebec are sometimes called the Flood Zone Maps or CZI (Cartes de Zones Inondables). The CZI are used by the Regional Municipal County (RMC) and have to be included within the general county planning called "schéma d'aménagement et développement" (SAD). The RMC is a supralocal entity that includes a group of municipalities and has some legal responsibilities such as creating and implementing the $\mathrm{SAD}$. The SAD is developed with concertation of all municipalities and is implemented within the municipality's urban development planning.

In Québec, regulatory flood maps generally follow the French approach, showing the area behind levees as part of the regulatory flood prone area. However, a few areas have been exempted from depicting residual risk behind levees. One of these, Sainte-Marthe-sur-le-Lac in the suburbs of Montreal, experienced a levee breach in April 2019, sending 5,000 residents fleeing to higher ground during devastating floods. This event has reopened (once more) the debate of whether and how to acknowledge residual risk behind levees. The 2017 and 2019 floods highlighted the vulnerability of several communities living behind levees within the actual regulatory framework in which exemptions can occur in Quebec.

While neither Canada nor Quebec have created a flood insurance system, up to 2015, home insurance did not cover natural flood disasters, which were to be covered in part by federal and/or provincial specific funding programs after significant floods. These programs generally cover only limited items and house types, so usually residents must pay much of the damages. Since 2015, insurance companies have begun to offer flood insurance in provinces, and the Insurance Bureau of Canada recently submitted a report to the federal government about options to insure flood damages across the country. Following the 2017 flood, the Québec government offers two alternative choices to homeowners whose homes have flooded. One option is for the government to pay up to a cumulative CA $\$ 100,000$ for all future flood damages. The second option is for the government to pay CA\$200,000 to buy the house or CA $\$ 250,000$ to buy the house and the land. The rationale behind the program is that a homeowner possessing a house in an area that is repetitively flooded is likely to opt for the second choice.

\section{Technical aspects of the regulatory flood maps in the USA, France and Quebec}

There are two main steps to create a regulatory flood map. The first step is to define the portion of the geomorphological floodplain (the maximum flood prone area) where the regulations will apply. Hazard maps can be created using different types of information: hydrologic and hydraulic modeling (HHM), information from historical floods, ecological information such as the limits of the riparian forest or geomorphological information based on geomorphic indicators (figure 1). Once the boundaries of the official regulatory flood prone area are established, the second step is to define the zones which will be linked to different regulations, to produce the actual regulatory flood map (Serra-Llobet et al., in review).

In the USA, FIRMs are generated by FEMA (the Federal Emergency Management Agency) for riverine and coastal floods following their own mapping standards and guidelines. Nowadays most maps are generated using mainly HHM, formerly 1D models, but with the availability of HEC-RAS 2D in the last 5 years, most flood hazard maps are done with HEC-RAS 2D (USACE-HEC 2021). The maps are prepared at a scale of $1: 6,000$ for the 10-, 50-, 100-, and 500-yr floods. The regulatory flood prone area, called the Special Flood Hazard Area (SFHA), 
is defined for the 100-yr flood elevation (also referred to as the Base Flood Elevation, BFE). The BFE is what the local floodplain ordinance adopted by the community is written to. There are two main levels of hazard represented in these maps, the 100y flood, also called the "high risk area", and is subdivided into the "floodway" and the "flood fringe", and the area between the $100 \mathrm{y}$ and the $500 \mathrm{y}$ flood, which is called "low or medium risk area". The floodway is defined as the channel of a river or other watercourse and the adjacent land areas that must be reserved in order to discharge the base flood without cumulatively increasing the water surface elevation more than a designated height (which in general is 1 foot) (figure 2.a). The flood fringe corresponds to the area between the boundary of the floodway and the $100 \mathrm{y}$ flood.

FIRMs are based on existing conditions. However, current FEMA guidelines (FEMA 2018) suggest that "flood hazard determinations should be based on conditions that are planned to exist in the community within 12 months following completion of the draft Flood Insurance Study (FIS) report". This can include works projects in progress, including channel modifications, hydraulic control structures, storm-drainage systems, and other flood protection projects." FEMA future conditions do not take into account future land-use development, such as urban growth, or climate change.

In France, the regulatory flood maps of the PPR-i are also based on hazard maps (1: 5000) and are produced at the level of the "commune" (municipality) or a group of "communes", following the hydraulic logic (watershed scale) rather than administrative logic, by combining different hydraulic parameters depending on the regions of France. They include riverine and coastal flooding and in some occasions flash flooding. The hydraulic modeling represents the "crue de référence" (reference flood), which corresponds to a 100-year flood or a larger historical flood, whichever is higher (Figure 2.b.). The regulatory flood maps are created following general guidelines defined at a national level, but the State might also decide on specifics related to the design or subclasses. Although maps in France also started with 1D now many of them are made using 2D modelling.

In France, maps are prepared using different frequencies depending on the municipality. In the north of France, maps are commonly based on a combination of duration of submersion and water depth, while in the south, with a Mediterranean climate, maps are based on velocity and water depth. There are three levels of hazard represented in this maps, high hazard zone, called the aléa forte (strong hazard area), a medium hazard zone, the aléa modéré (medium hazard area), and a low hazard zone, the aléa résiduel (residual hazard area).

In 2011, one year after Storm Xynthia, the Circular $27 / 07 / 11$ called for climate change to be taken into account in the PPR-1, assuming a $60 \mathrm{~cm}$ increase in sea level by 2100 for coastal flooding. However, as a circular, it does not impose a regulatory obligation. In 2019, the government defined once and for all the different concepts and principles and integrate them into the Environmental Code, the so-called Decree Project Concerning Risk Prevention Plans for Riverine and Coastal Flooding (Project of Décret relatif aux plans de prévention des risques concernant "aléas débordement de cours d'eau et submersion marine") (MATE-METL, 2002; MTES, 2001; MTES 2018; MTES, 2019).

In Canada, the provinces have flexibility to regulate as they choose. Federal guidelines exist (Natural Resources Canada 2018), but Quebec has its own guidelines, and maps must be approved by the Direction de l'expertise hydrique (DEH), a service within the Environment Ministry at the provincial level. In Québec, the boundaries of the regulatory flood prone maps, the Flood Zone Maps, is generally defined using HHM for both $20 \mathrm{y}$ and $100 \mathrm{y}-$ floods at a 1:2000 scale, but they can also include information from historical floods and, more recently, from hydrogeomorphological analyses. The methodological choice to produce the maps depends on the stakes at risk within the floodplain and on the financial support available to produce the maps. Biological information is also used to define the 'zone littoral' (riparian zone) (2y flood), an area that should be preserved to ensure the connectivity of the river with the immediate floodplain.

In general, two main areas are represented in the CZI maps: the "zone the fort courant" (high probability zone) is the area flooded by a $20 y$ recurrence flood while the "zone the faible courant" (low probability zone) is the area flooded between the $20 \mathrm{y}$ and the $100 \mathrm{y}$ recurrence flood. On a few occasions the reference flood has been defined at a watershed scale using HHM information complemented by historical floods and hydrogeomorphological information. With this method, Quebec is now expanding to goals of the regulatory flood maps towards a more sustainable approach to manage floods which is not only focused on reducing flood risk in hazardous zones (social goals) but also to identify areas of river connectivity of channel migration to ensure the natural processes that are necessary for the well-functioning of floodplain ecosystems (ecological goals), especially in non-urbanized areas. FEMA region $\mathrm{X}$ is now replicating this approach in some regions of the west coast of the USA, adapting it within the National Flood Insurance Program (NFIP) limitations, meaning that they can only map channel migration zones within the $100 \mathrm{y}$ flood area, in these areas land use restrictions may be stronger.

In Quebec there are no clear guidelines to account for climate change when defining future flood prone areas. Suggestions are made by various agencies in the Province, but at the moment, no consensus appears to have been reached. For example, there is a suggestion to add $30 \mathrm{~cm}$ to the modelled flood level, while another suggestion is to use the hydrologic projections from the Atlas Hydrologique du Québec Méridional. These suggestions are provided within the new program for mapping by the Ministère des affaires municipales et de l'habitation following the 2017 flood events.

\section{Conclusions: Key Differences Among the Three Approaches}

In recent years, the USA, Quebec and France have all experienced severe floods that have both challenged and strengthened their approaches to managing floods. The 
three share a similar approach to deal with flood risk: the use of regulatory maps to reduce exposure and vulnerability to flood hazard. In their flood-related policies there is a clear focus on the use of non-structural measures linked to mitigation such as land use planning, building codes, emergency measures, or risk communication. However, especially in the USA most attention has been paid to managing the 'design flood' (the 100-year flood in the USA), and less to the areas behind levees (once the levee is accredited), which are subject to the residual risk of levee breach or overtopping (low probability high consequences) (Hutton et al., 2019). Although FEMA's policy has been to show the residual risk in areas protected by levees in the FIRM, the main challenges in the USA policy is the voluntary nature of the NFIP, which makes each community unique in the way they manage residual risk behind levees.

Although the three countries started with the same idea (to use regulatory maps to reduce exposure and vulnerability to flood hazard), because of their geographic, demographic, governance, and cultural differences, the implementation of this concept ends up being very different. While in France the area behind levees is part of the regulatory flood prone area, and land use restrictions, building codes, emergency measures and risk communication are mandatory, in the USA the area behind levees is only shown as part of the regulatory flood prone area if the levee is not accredited. Behind FEMA accredited levees this area appears as "Shaded Zone X", land use restrictions are not mandatory, which has created a false sense of security which has incentivized the increase of developments in these areas, what is known as the "levee effect" (White 1945). In Québec, regulatory flood maps in general follow the French approach, to show the area behind levees as part of the regulatory flood prone area. However, a few areas have been exempted from depicting residual risk behind levees, of which one, SainteMarthe-sur-le-Lac (Montreal) flooded from a levee breach in April 2019, bringing the policy again into public scrutiny.

\section{Acknowledgements}

We thank the Institute of Advanced Studies (IMéRA) of Aix-Marseille University, the Laboratory of Excellence (Labex) OT-Med in Aix-en-Provence, and the Canadian Studies Program of the University of California at Berkeley's Sproul Research Fellowship for their support to this research.

\section{References}

Barraqué, B. (2014). The common property issue in flood control through land use in France. J. Flood Risk Management. doi.org/10.1111/jfr3.12092.

Burby, R. (2001) Flood Insurance and floodplain management: the US experience. Environmental Hazards. Vol. 3, pp. 111-122.
Demers, S., Olsen, T., Buffin-Belanger, T., Marchand, JP, Biron, P., Morneau, F. (2014). L'hydrogéomorphologie appliquée à la gestion de 1 'aléa d'inondation en climat tempéré froid : l'exemple de la rivière Matane (Québec). Physio-géo, 8, 67-88. doi : 10.4000/physio-geo.3813

Eisenstein, W., Kondolf, G.M., Cain, J. (2007). ReEnvisioning the Delta: Alternative futures for the heart of California. Berkeley, California: Institute of Urban and Regional Development, University of California, Berkeley.

FEMA (Federal Emergency Management Agency) (2018) Guidance for Flood Risk Analysis and Mapping: Levees. Accessed online at: https://www.fema.gov/media-librarydata/1524085432002-

e9d771ca450758832f64f8e4f1ff2779/Levee_Guidance_F eb_2018.pdf

Hutton N.S., Tobin G.A. and Montz B.E. (2019). The levee effect revisited: Processes and policies enabling development in Yuba County, California. J Flood Risk Management. 12:e12469.

https://doi.org/10.1111/jfr3.12469.

Johnson, K.A., Wing, O.E.J., Bates, P.D. et al. (2020). A benefit-cost analysis of floodplain land acquisition for US flood damage reduction. Nat Sustain 3, 56-62. https://doi.org/10.1038/s41893-019-0437-5.

de Loë, R. (2000). Floodplain management in Canada: overview and prospects. Canadian Geographer, 44(4), 355-368.

Millerd, F., Dufournaud, C., Schaefer, K. (1994). CanadaOntario flood damage reduction program case studies. Canadian Water Resources Journal, 19(1), 17-26.

MATE-METL (Ministère de l'Aménagement du territoire et de l'environnement - Ministère de l'équipement, des transports et du logement) (2002) Circulaire du 30 avril 2002 relative à la politique de l'Etat en matière de risques naturels prévisibles et de gestion des espaces situés derrière les digues de protection contre les inondations et les submersions marines. Accessed online at: http://www.bulletin-officiel.developpementdurable.gouv.fr/fiches/BO200219/A0190045.htm.

MTES (Ministère de la Transition Écologique et Solidaire) (2011) Circulaire du 27/07/11 relative à la prise en compte du risque de submersion marine dans les plans de prévention des risques naturels littoraux. Accessed online at: https://aida.ineris.fr/consultation_document/6925 .

MTES (Ministère de la Transition Écologique et Solidaire) (2018) Project of Décret relatif aux plans de prévention des risques concernant les « aléas débordement de cours d'eau et submersion marine ». Accessed online at: http://www.consultations-publiques.developpementdurable.gouv.fr/projet-de-decret-relatif-aux-plans-deprevention-a1848.html. 
MTES (Ministère de la Transition Écologique et Solidaire). (2019). Décret no 2019-715 du julliet 2019 relatif aux plans de prévention des risques concernant les « aléas débordement de cours d'eau et submersion marine ». Journal Officiel de la République Française. Available at :

https://www.legifrance.gouv.fr/loda/id/JORFTEXT00003 $8730822 /$.

Natural Resources Canada (2018). Federal Flood Mapping Framework, Version 2.0. General Information Product 112e, 24pp.

Serra-Llobet, A, R Tourment, A Montané, T BuffinBelanger. Managing residual flood risk behind levees: comparing USA, France, and Quebec (Canada). (in review).

USACE-HEC (US Army Corps of Engineers, Hydrologic Engineering Center) (2021). HEC RAS 2D User's Manual. US Army Corps of Engineers, Hydrologic Engineering Center, Davis, California. Available online at https://www.hec.usace.army.mil/confluence/rasdocs/r2du $\mathrm{m} /$ latest Accessed January 2021.

White, G.F. (1945). Human Adjustments to Floods, University of Chicago, Department of Geography, Chicago, IL. 
FIGURE 1. Types of information that can be used to create a flood map.
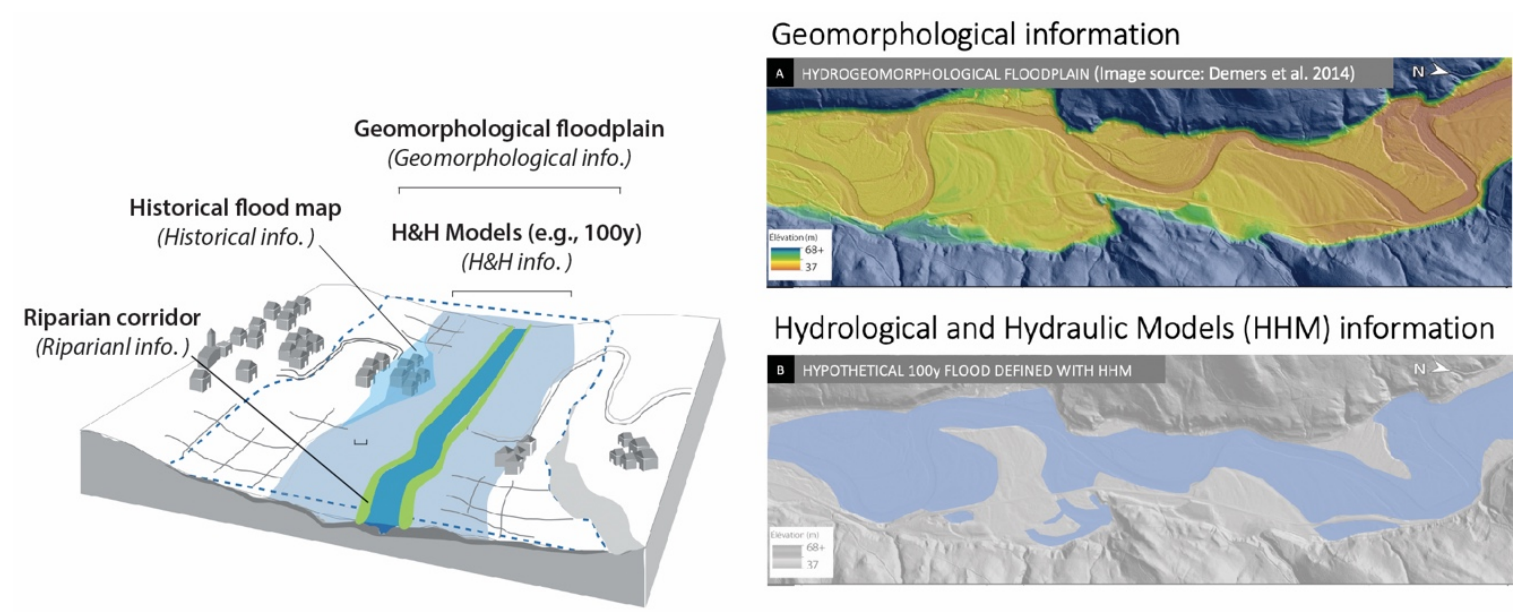

Biological information

Hydrological and Hydraulic Models (HHM) information
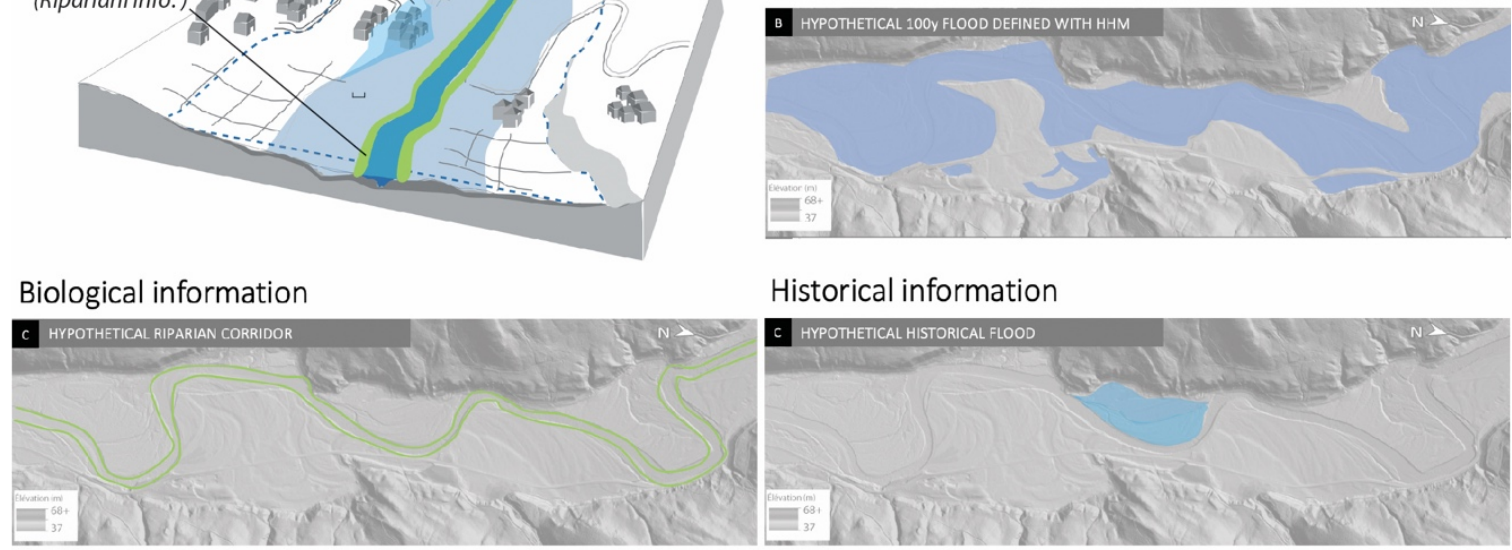

Historical information

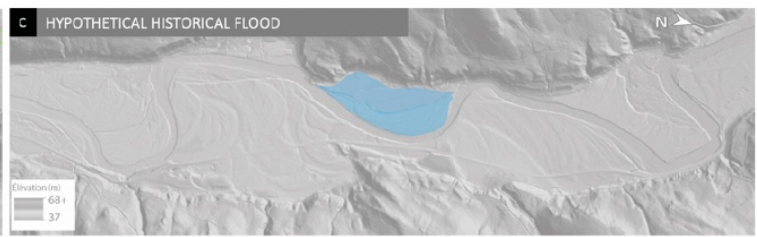

Image: Serra-Llobet and Buffin-Belanger 
FIGURE 2. Different methods and types of information used to identify the main flood prone areas depicted in regulatory flood maps in (a) the USA, (b) France and (c) Quebec.

\section{METHODS AND TYPES OF INFORMATION USED TO DEFINE HIGH, MEDIUM, AND LOW PROBABILITY AREAS}

USA FIRM

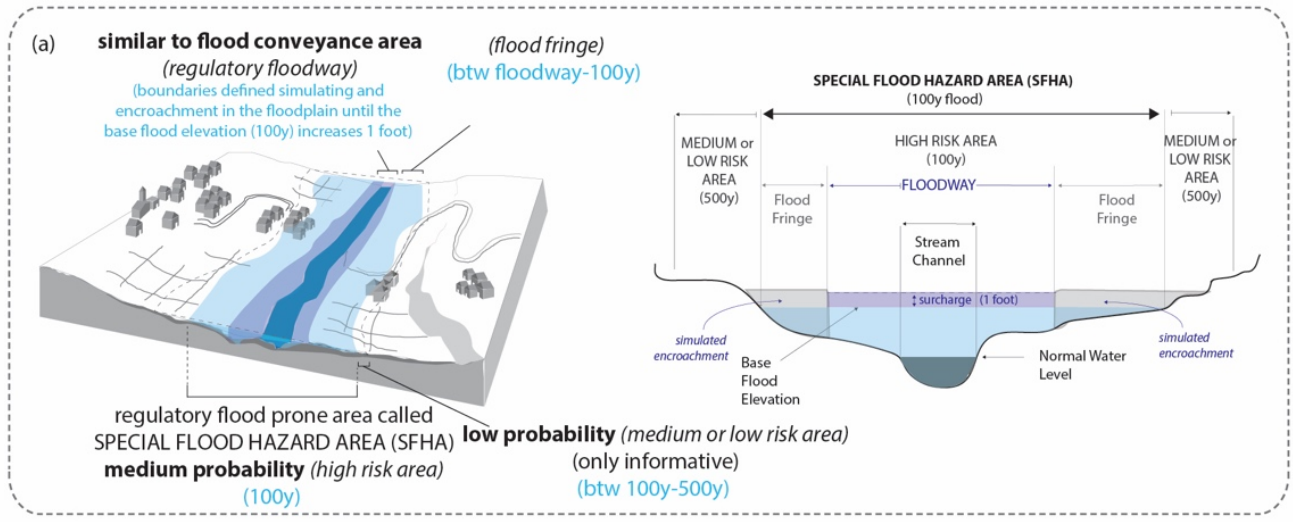

FRANCE PPRi

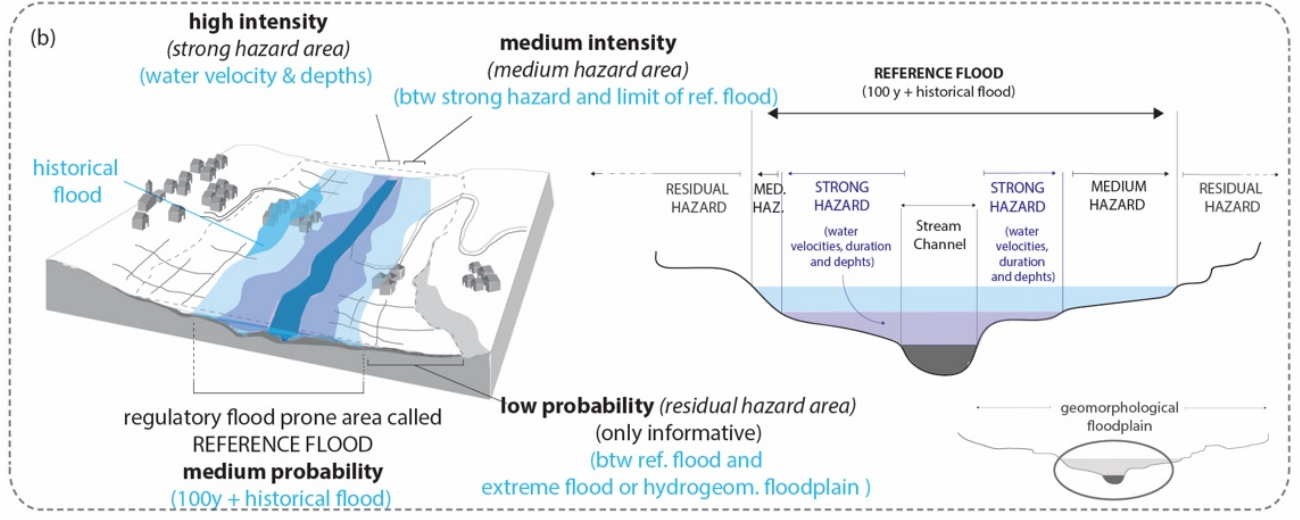

\section{QUEBEC CZI (PPRLPI)}

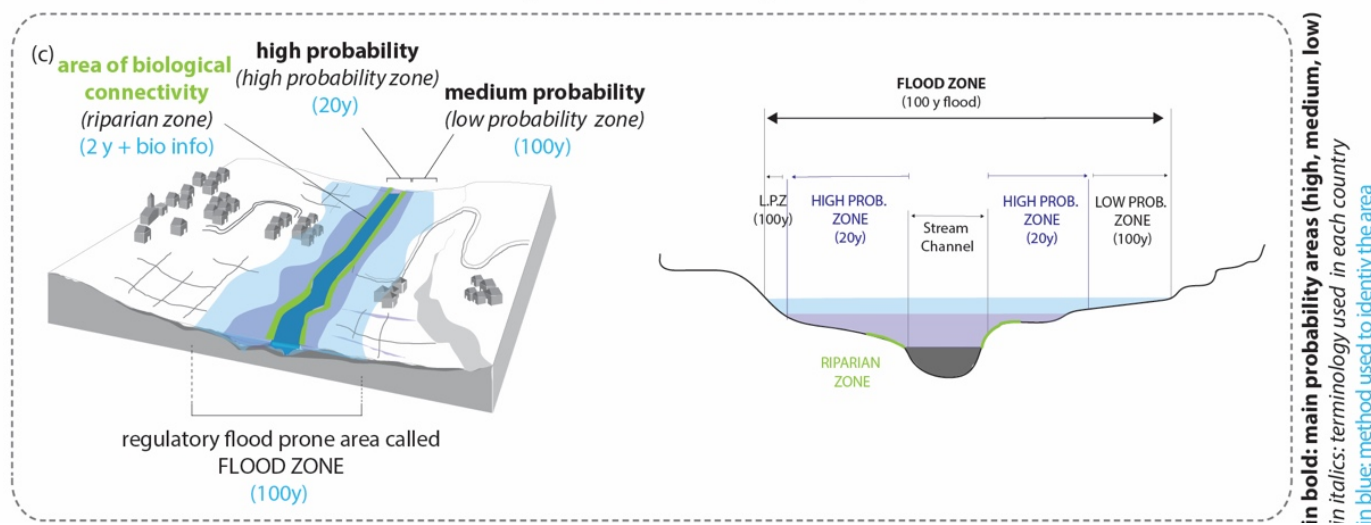

